studies would be necessary to confirm that the results presented here are a true reflection of the prevalence of hepatitis $B$ virus in the whole country and whether tropical ulcers have a role in its transmission. These data, however, indicate the desirability of vaccinating all Gilbertese children against hepatitis $B$ virus at a very early age, preferably at birth, irrespective of maternal hepatitis $\mathrm{B}$ e antigen state. I hope that the price of hepatitis $B$ vaccines will soon be within reach of the modest health budgets of countries such as Kiribati so that this vaccine can be included in the already successful vaccination programme currently instituted by the country's primary health care team.

This survey would have been impossible without the enthusiastic cooperation of everyone I met in Kiribati. I thank Dr T Tetaua, principal medical officer, for permission to work in Kiribati, Mr Tonganabea Taam and Mrs N Tarena for invaluable help with field collections, and Mr T Biribu and staff for laboratory help. I am very grateful to Professor J E Banatvala for his advice and permission to perform the assays in his department. I also thank Drs Joe Cobb and Sue Turner in Kiribati and Professor A J Zuckerman, Mr John Bertram, Miss Asha Senapati, Dr R P H Thompson, and $\mathrm{Dr} \mathrm{K}$ Cruikshank in England, who gave me invaluable advice and help. I am grateful to Miss Christina Fox and Miss Elaine Ruddock for typing the manuscript.

This work was supported by the Medical Research Council (Rogers Fund), the British Medical Students' Trust, and St Thomas's Hospital Medical School. Equipment was generously supplied by FBG Trident Ltd and reagents by Abbott Laboratories, Chicago.

\section{References}

1 Zhuang H, Coulepis AG, Gust ID, Zimmet P, Taylor R, Nemaia HT. A cross sectional study of markers of hepatitis B infection in Niue. NZ Med J 1983;96:330-2.

2 Gust ID, Dimitrakakis $M$, Bott F, et al. Studies on hepatitis B surface antigen and antibody in Nauru. II. Distribution amongst Gilbert and Ellice (Tuvala) islanders. Am f Trop Med Hyg 1978;27:1206-9.

3 Gust ID, Dimitrakakis M, Zimmet P. Studies on hepatitis B surface antigen in Nauru. I. Distribution amongst Nauruans. Am $\mathcal{F}$ Trop Med Hyg 1981;27:1030-6.

4 Williamson HG, Gust ID, Dimitrakakis $M$, et al. Serological markers of hepatitis B infection in Niue children. NZ Med f 1985;98:275-7.

5 Mazzur S, Bastiaans MJS, Nath N. Hepatitis B virus (HBV) infection among children and adults in the Solomon Islands. Am $\mathcal{F}$ Epidemiol 1981;113:510-9.

6 Simmons GC, Yeong ML, Lee SP. The association of hepatitis B viral infection and hepatocellular carcinoma in New Zealand. NZ Med f 1983;96:669-71.

7 Zuckerman AJ. Primary hepatocellular carcinoma and hepatitis B virus. Trans $R$ Soc Trop Med Hyg 1982;76:711-8.

8 King H, Taylor R, Zimmet P, et al. Non-insulin-dependent diabetes (NIDDM) in a newly independent Pacific nation: the Republic of Kiribati. Diabetes Care 1984;7:409-15.

9 Gamble A. A pattern of islands. London: John Murray, 1952.

10 Polakoll G. Immunisation of children at high risk of hepatitis B. Br Med $\mathcal{F}$ 1986;285:1294-5.

11 Zuckerman AJ. Priorities for immunisation against hepatitis B. Br Med f 1982;284:686.

12 Beasley RP, Trepo C, Stevens CE, Szmuness W. The e antigen and vertical transmission of hepatitis B surface antigen. Am f Epidemiol 1977;105:94.

13 Whittle HC, McLachlan K, Bradley AK, et al. Hepatitis B infection in two Gambian villages. Lancet 1983; i: 1203-6.

14 Karayiannis P, Novick DM, Lok ASF, Fowler MJF, Moniardino J, Thomas HC. Hepatitis B virus DNA in saliva, urine, and seminal fluid of carriers of hepatitis $\mathrm{B}$ e antigen. Br Med $\mathcal{J}$ 1985;290:1853-5.

15 Botha JF, Ritchie MJJ, Dusheiko GM, Mouton HWK, Kew MC. Hepatitis B virus carrier state in black children in South Africa. Lancet 1984;i:1210.

(Accepted 25 November 1986)

\title{
Micturition and the mind: psychological factors in the aetiology and treatment of urinary symptoms in women
}

\author{
A J MACAULAY, R S STERN, D M HOLMES, S L STANTON
}

\begin{abstract}
The mental state of 211 women attending a urodynamic clinic was assessed using questionnaires. Patients with genuine stress incontinence had scores comparable with other patients with longstanding physical complaints. Patients with sensory urgency were more anxious than those with genuine stress incontinence. Patients with detrusor instability were as anxious as patients with sensory urgency and in addition had higher scores on the hysteria scale. A subset of patients (roughly a quarter of the total) was identified, comprising members of all three diagnostic groups, for whom urinary symptoms rendered life intolerable. These patients were as anxious, depressed, and phobic as psychiatric inpatients, emphasising the serious psychological morbidity experienced by patients with urinary symptoms.

Fifty patients with detrusor instability or sensory urgency entered a randomised trial comparing psychotherapy, bladder drill, and propantheline. The psychotherapy group significantly
\end{abstract}

Department of Psychiatry, St George's Hospital, Tooting, London SW17 ORE

A J MACAULAY, MSC, MRCPSYCH, senior registrar

R S STERN, MD, FRCPSYCH, consultant psychiatrist

Department of Obstetrics and Gynaecology, St George's Hospital

D M HOLMES, BSC, MRCOG, clinical research fellow

S L STANTON, FRCS, MRCOG, consultant and senior lecturer, urodynamic unit

Correspondence to: Dr Macaulay. improved on measures of urgency, incontinence, and nocturia, though not on frequency. Bladder training was an effective treatment for frequency and patients became less anxious and depressed. There was a modest improvement in frequency of micturition in patients given propantheline.

Frequency may be a learnt disorder which responds to the direct symptom oriented approach of bladder training. Patients with urgency and nocturia predominating might derive more benefit from psychotherapy.

\section{Introduction}

Chronic urgency, frequency, and incontinence are troublesome lower urinary tract symptoms which occur in one fifth of women. ${ }^{1}$ The most important underlying conditions are genuine stress incontinence, idiopathic non-neuropathic detrusor instability, and sensory urgency. Genuine stress incontinence is caused by incompetence of the bladder neck and is conventionally treated by pelvic floor exercises and surgery. Most patients presenting with incontinence have urge type leakage due to sensory urgency or detrusor instability. ${ }^{2}$ The two conditions are distinguished by cystometry, which gives normal results in sensory urgency but shows a pressure rise greater than $15 \mathrm{~cm} \mathrm{H}_{2} \mathrm{O}$ in detrusor instability. Neither disorder responds satisfactorily to conventional management such as surgery or drug treatment. ${ }^{3}$ Psychological approaches have shown some promise. Frewen offered a complete package of inpatient treatment, comprising a bladder diary, bladder retraining, anxiolytic and anticholinergic medication, and supportive care ${ }^{4}$ His results were impressive $(82.5 \%$ of patients cured) but there were insufficient 
objective psychometric or urodynamic outcome measures and it was unclear which were the most important therapeutic aspects.

The aim of the first part of this study (clinic survey) was to assess the mental state of patients attending a urodynamic clinic. The second part (treatment trial) was designed to elucidate some of the factors that might be clinically relevant, therapeutic, and feasible in the treatment of sensory urgency and detrusor instability.

\section{Patients and methods}

\section{CLINIC SURVEY}

Patients were asked to rate their symptoms using visual analogue scales. In addition, three standardised self rating questionnaires were used: the Spielberger (state/trait anxiety inventory, ${ }^{5}$ the Wakefield depression scale, ${ }^{6}$ and the Crown-Crisp experiential index. ${ }^{7}$ The CrownCrisp index provides a psychoneurotic profile on six subscales: anxiety, depression, phobic anxiety, obsessionality, functional somatic complaint, and hysteria. All three questionnaires provide normative data for different age groups. Comparisons with normal subjects and medical and psychiatric inpatients used the nearest age match possible.

Patients were allocated to a diagnostic category on the basis of history, physical examination, and (in most cases) cystometry. When clinically indicated cystoscopy or videocystourethrography was performed.

\section{TREATMENT TRIAL}

Patients with a cystometric diagnosis of detrusor instability or sensory urgency were invited to take part in the treatment trial. They were allocated at random to receive brief eclectic psychotherapy, bladder training, and medication. Patients in the psychotherapy group were seen by a psychiatrist (AJM) for eight to 12 weekly sessions of 50 minutes. This treatment was designed to offer the non-symptom oriented measures of support, counselling, and anxiety reducing aspects of the package as described by Frewen, ${ }^{4}$ but without bladder training. Bladder training was administered by the unit nurse. Patients were seen fortnightly for three months and again after one month (seven sessions). They were trained to ignore cues from the bladder at first sensation and to void at set times, eventually at bladder fullness. Pelvic floor physiotherapy exercises were also taught. The control group was given propantheline $15 \mathrm{mg}$ three times a day for three months.

Three outcome measures were used. Patients kept a week's bladder diary recording severity of symptoms. Mental state was assessed by the standardised questionnaires. Both of these parameters were recorded before starting treatment, immediately after completing three months of treatment, and at the end of the three month follow up period. Cystometry was performed during follow up.

The data were analysed in two ways. Firstly, variables were tested to see if there were any differences among the groups before treatment, after treatment, and at the follow up assessment. For continuous variables having reasonably normal distributions analysis of variance was used, while categorical variables were analysed by $\chi^{2}$ tests.

Secondly, the trial variables were examined within groups by paired $t$ tests to see if there were differences before and after treatment and at follow up.

\section{Results}

\section{CLINIC SURVEY}

Of 317 patients who attended the unit during the study, 106 were unable to complete the questionnaires: 70 were demented or unable to comprehend the questions; 12 had multiple sclerosis; eight did not have a sufficient grasp of English; 11 did not have their reading glasses; and five refused.

Questionnaires were completed by 211 patients (mean age 46.6 years, range 15-79). The most frequent diagnosis was genuine stress incontinence (66 patients $(31 \%))$. Fifty two patients $(25 \%)$ had sensory urgency and 32 $(15 \%)$ idiopathic detrusor instability. Twelve patients $(6 \%)$ had a mixed picture of genuine stress incontinence and either stress urgency or detrusor instability. Thirty seven patients (18\%) had urinary symptoms secondary to conditions such as multiple sclerosis. Twelve patients $(6 \%)$ failed to keep appointments for investigations or follow up but were included in the analysis except where this required allocation to a diagnostic category.

When asked to estimate the duration of urinary symptoms 135 patients (64\%) reported symptoms for two years or more, $34(16 \%)$ for one to two years, and $42(20 \%)$ for less than one year. There was no difference in the duration of symptoms among the diagnostic categories.
The question "generally how troubled are you by your bladder problems?" was presented as a visual analogue scale with the phrase "not troubled at all" (score 0 ) at one end and "makes life not worth living" (score 8 ) at the other. Twelve patients refused to answer this question. Almost half (95 patients) opted for a mid-point (score 4 or 5) on this scale. Seventeen scored 7 , and 30 scored 8 (symptoms made "life not worth living"). Included among these patients were eight with detrusor instability, 11 with sensory urgency, and 12 with genuine stress incontinence; this subgroup of 31 patients was additionally analysed separately and is referred to as subset $A$. The other 16 patients either had a mixed urodynamic diagnosis or did not have a primary urodynamic diagnosis.

The results of psychological assessment were evaluated in the 150 patients with pure genuine stress incontinence (that is, excluding mixed diagnosis), idiopathic detrusor instability, or sensory urgency. Figure 1 shows the Spielberger state anxiety scores. The pattern of results was very similar on the Spielberger trait scale and the anxiety subscale of the Crown-Crisp experiential index. On all scales the patients were more anxious than a normal population of similar age. Patients with genuine stress incontinence were no more anxious than general medical inpatients whereas patients with detrusor instability or sensory urgency were significantly: $(p<0.05)$ more anxious. Scores in subset $A$ were significantly higher $(p<0.05)$ and matched those of psychiatric inpatients whatever the diagnostic category. Patients with urodynamic disorders were more depressed than the normal population $(p<0.05)$ but not as much as psychiatric inpatients with depression (fig 2).

All three groups had scores above normal on the phobic anxiety subscale of the Crown-Crisp experiential index. Though significant $(p<0.05)$, the difference between the means of normal subjects and the patients with urodynamic disorders was only one point on the scale. Scores in subset A were significantly raised: the mean score of the patients with detrusor instability was higher than that of the group with sensory urgency, which in turn was higher than that in the patients with genuine stress incontinence.

On the obsessionality and functional somatic complaint subscales group mean scores were similar and not significantly different from normal.

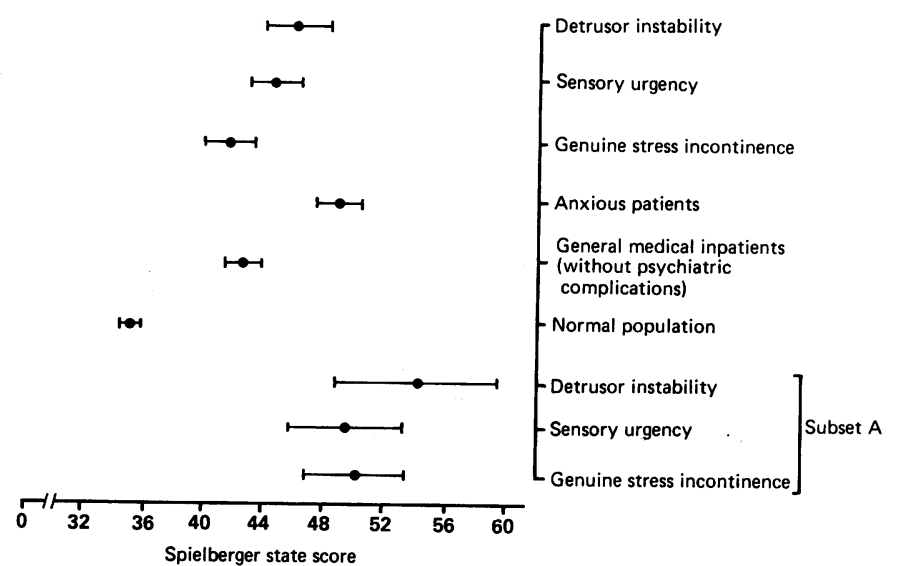

FIG 1-Mean Spielberger state anxiety scores. Bars are SEM.

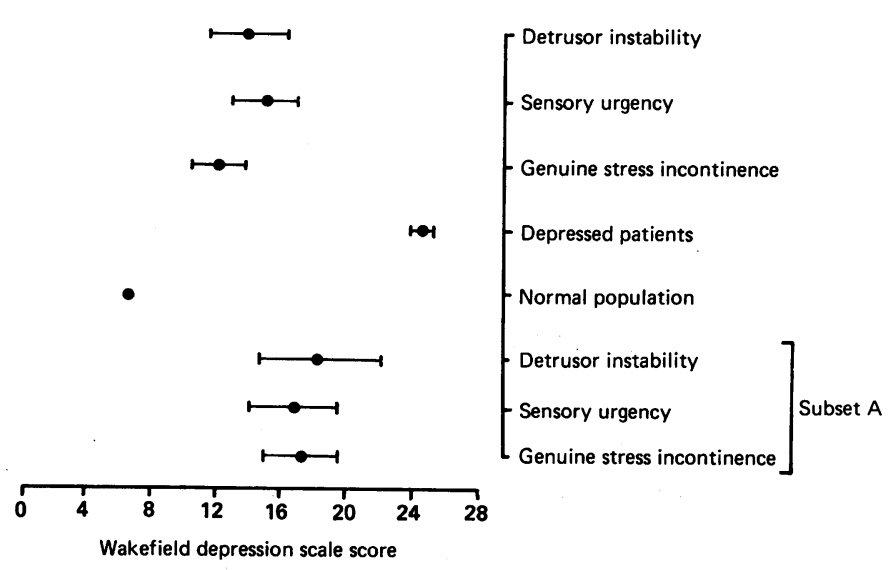

FIG 2-Mean Wakefield depression scale scores by diagnostic group. Bars are SEM. 
Patients in subset A, however, scored as highly on obsessionality as patients with psychiatric illness. In contrast with trends in other measures, patients in subset $A$ with genuine stress incontinence had significantly more somatic complaints with scores equivalent to those of psychiatric patients.

All patients with urodynamic diagnoses had abnormally high scores on the hysteria scale. The mean score for the group with detrusor instability was significantly higher $(p<0.05)$ than the means in the other two diagnostic groups. There was a negative correlation between the score on the hysteria scale and age. Though highly significant $(p<0.001)$, it accounted for only $4 \%$ of the variance.

\section{TREATMENT TRIAL}

After cystometry 52 patients were invited to take part in the treatment trial. Two declined, leaving 26 with detrusor instability and 24 with sensory urgency. Nineteen patients were allocated to psychotherapy (10 with detrusor instability, nine with sensory urgency), 16 to bladder drill (eight with detrusor instability, eight with sensory urgency, and 15 to receive propantheline (eight with detrusor instability, seven with sensory urgency). One patient from each group withdrew before treatment. Thus 47 patients were evaluable for response.

In the psychotherapy group there was a modest trend towards improvement in bladder capacity (mean before treatment $393 \mathrm{ml}$, mean after

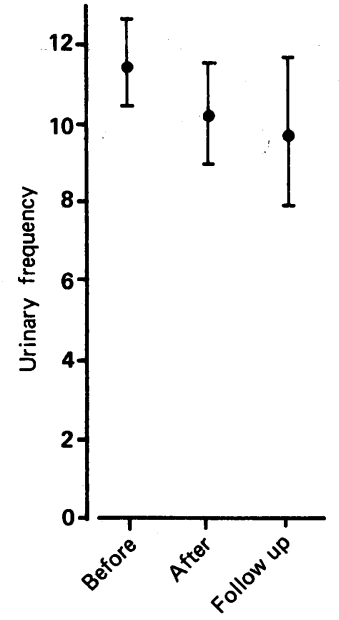

Psychotherapy<smiles>CCCCCCCCCCCCCCCCCC</smiles>

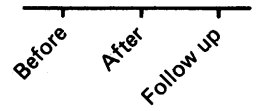

Bladder drill

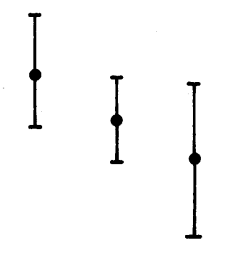

FIG 3-Mean urinary frequency (number of voidings) during day. Bars are SEM.

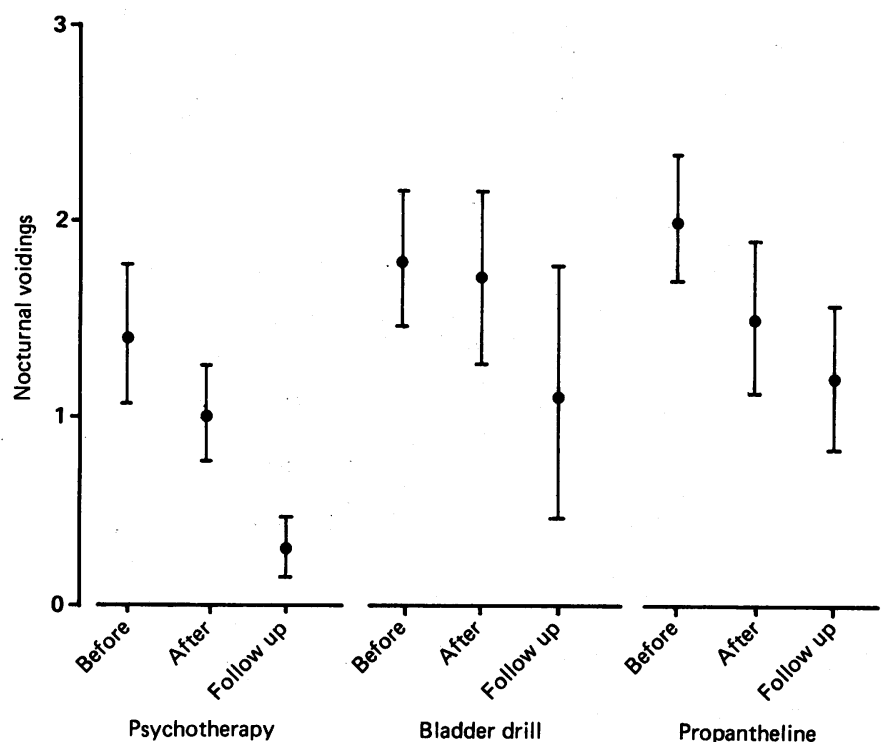

FIG 4-Mean number of voidings at night. Bars are SEM.

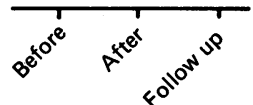

Propantheline

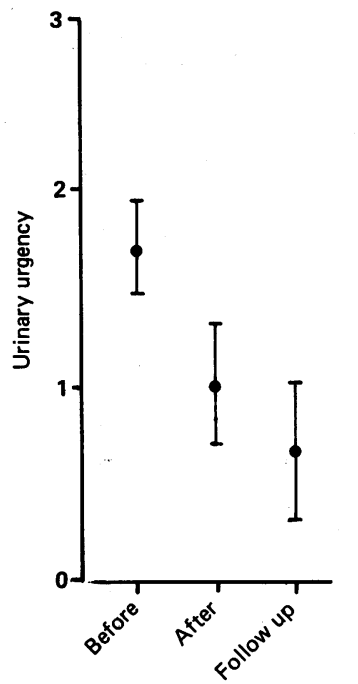

Psychotherapy

FIG 5-Mean urinary urgency scores, $0=$ Not a symptom $1=$ Occurs less than twice a day. $2=$ Occurs less than on every occasion but more than twice during day. 3 = Occurs on every occasion before micturition, or more often. Bars are SEM.
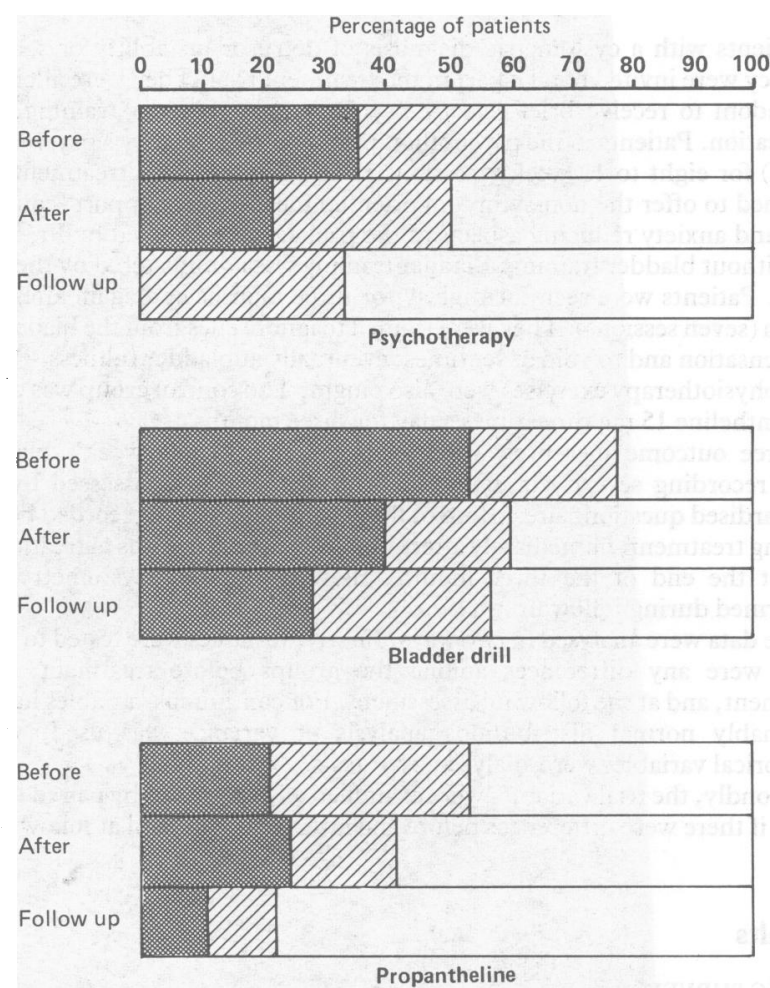

FIG 6-Percentages of patients with urinary incontinence before and after treatment and at follow up. $\square$ Severely troubled (dampness more than seven times a week or leakage necessitating change of clothing more than once a week, or both). $/ /$. Minor symptom (dampness on fewer than seven occasions a week). $\square$ Symptom free.

treatment $414 \mathrm{ml}$ ) and in first sensation (volume at which the patient is first aware of bladder fullness; $107 \mathrm{ml}$ compared with $142 \mathrm{ml}$ ). Neither was statistically significant. By contrast, there was a clear improvement in nocturia (before treatment $v$ follow up $\mathrm{p}<0.05$; fig 4 ), urgency (before treatment $v$ after treatment $\mathrm{p}<0.05$; fig $5 ; \chi^{2}$ test), and incontinence (before treatment $v$ follow up $p<0.01 ;$ fig $6 ; \chi^{2}$ test). There was no significant change in any psychological measure except for fewer somatic symptoms after treatment $(p<0.05)$

Treatment in the bladder training group was associated with cystometric improvements in mean detrusor pressure rise $\left(45.5 \mathrm{~cm} \mathrm{H} \mathrm{H}_{2} \mathrm{O}\right.$ before 
treatment, $29.5 \mathrm{~cm} \mathrm{H} \mathrm{H}_{2} \mathrm{O}$ after treatment; $\mathrm{p}<0.05$; and in first sensation of bladder fullness (mean $110 \mathrm{ml} v 150 \mathrm{ml} ; \mathrm{p}<0.05$ ). In parallel there was a change in psychoneurotic profile, with a reduction in state anxiety (before treatment $v$ follow up $\mathrm{p}<0.005$ ); and depression (paired $t$ test, before treatment $v$ follow up $\mathrm{p}<0.05$ ). There was only modest improvement in urgency, nocturia, and urinary incontinence. Urinary frequency improved; though statistical analysis just failed to reach significance (before treatment $v$ follow up $p=0.07$; fig 3 ), the mean follow up score was within the normal range (below 7) and the associated improvement in psychoneurotic profile suggested that the change was clinically meaningful.

Results of cystometry in patients given propantheline were similar to those in the psychotherapy group, with some benefit in terms of first sensation of bladder fullness $(70 \mathrm{ml} v 137 \mathrm{ml} ; \mathrm{p}=0.06)$; and bladder capacity $(323 \mathrm{ml} v 368 \mathrm{ml}$; NS). Though urinary frequency improved, the actual difference in mean number of voidings during the day was modest (before treatment $10.8 v 8.3$ at follow up; $p<0.005$ ); and at follow up frequency still rated as a symptom. There was no change in other urinary symptoms. There was a significant reduction in state anxiety (paired $t$ test, before treatment $v$ follow up $p<0.05$ ) but other psychoneurotic measures were unchanged.

\section{Discussion}

Though not life threatening, chronic urinary symptoms are a source of appreciable morbidity and may become incorporated into the patient's lifestyle and personality. It is to be expected that the psychoneurotic profile might change as a result. As noted before, ${ }^{28}$ patients with urodynamic disorders were abnormally anxious. This change was particularly noticeable in patients with detrusor instability and sensory urgency, suggesting that anxiety is an important correlate of the symptoms of urgency, frequency, nocturia, and urge incontinence.

The patients also scored highly on measures of depression. Patients with urodynamic conditions do not have a depressive illness but they do have a depressed mood, as might be expected in any patient with a longstanding distressing condition.

Scores on the hysteria subscale were generally high and most abnormal in patients with detrusor instability. This concurs with the results of two studies ${ }^{10}$ but contrasts with one. ${ }^{11}$ The hysteria scale possibly assesses aspects of personality relating to self esteem and self confidence. This might imply a causal relation; patients with similar symptoms but normal findings on cystometry (the sensory urgency group) had lower scores on a level with patients with genuine stress incontinence. Results on the functional somatic scale suggest that patients with urodynamic disorders do not present with multiple complaints. This lends credence to the relevance of their existing symptoms.

Thus the psychological profiles of the three main diagnostic groups were different; this cannot be explained on the basis of age or duration of symptoms.

A substantial proportion of our patients (roughly a quarter) complained that life was not worth living because of their urinary symptoms. These patients were as anxious, depressed, and phobic as psychiatric inpatients. Possibly an abnormal mental state may generate urinary symptoms. ${ }^{12}$ Conversely, chronic urinary problems are a genuine source of stress; a quarter of the patients with genuine stress symptoms (with undoubted anatomical abnormalities) also claimed that their urinary symptoms rendered life intolerable.

Other studies of patients with urodynamic conditions have tried to assess multiple treatments. ${ }^{413}$ Our trial aimed at studying individual aspects of potential therapeutic benefit in as "pure" a form as possible. Thus bladder training was intended to be devoid of the supportive, non-behavioural aspects which usually accompany the treatment in clinical practice. The training may not have been carried out most efficaciously; "warmth, genuineness, and empathy" may be important, non-specific components. ${ }^{14}$ Improvement in frequency was accompanied by reduction in state anxiety and depression, suggesting that patients rated this improvement as an important gain.

The psychotherapy administered was intentionally broad based and included support, encouragement, and reassurance as well as the opportunity to resolve intrapsychic conflict and marital discord. All patients had the same psychotherapy but valued different aspects of it. Some discussed and worked through conflicts and anxieties, but others appeared simply to value the supportive aspects. The results show that psychotherapy can have an impact on urinary symptoms. Nocturia, urgency, and incontinence all improved significantly. Indeed, no patient given psychotherapy had more than minor incontinence at follow up. Frequency, however, was unaltered, possibly because different mechanisms operate in the aetiology and treatment of this symptom. We should expect the psychotherapy group to show psychological changes, both because of the nature of their treatment and because their urodynamic symptoms improved; however, there was no appreciable change in the psychological ratings. Increased self awareness and introspection may have masked any benefit, which is supported by the finding that there was significant improvement on the somatic complaints scale-questions which all relate to physical correlates of anxiety. This explanation, however, can be only speculative.

For the group given propantheline there was no benefit in terms of suppression of detrusor activity; this was perhaps surprising, given that the rationale for using this drug was to inhibit cholinergic mediated detrusor contraction. There was, however, improvement in first sensation of bladder fullness, frequency, and state anxiety.

A cost-benefit analysis showed that psychiatric treatment for urinary symptoms is less expensive than gynaecological management. ${ }^{15}$ The increased availability and appropriate application of bladder training and psychotherapy would produce benefits to patients and savings for the health service.

This work forms part of the MD thesis submitted to the University of London by AJM, which was supervised by RSS. AJM was supported as a clinical research fellow by the Wellcome Trust (18 months) and the special trustees of St George's Hospital, Tooting (six months). AJM is also grateful to SLS and other staff of the urodynamic unit at St George's for all their help and guidance. Thanks are due to $\mathrm{A}$ Bhat, of the department of psychiatry, St George's Hospital Medical School, for help with the statistical analysis.

\section{References}

1 Bungay GT, Vessey MP, Mcpherson CK. Study of symptoms in middle life with special reference to the menopause. $\mathrm{BrMed}$ F 1980;281:181-3.

2 Jeffcoate TNA, Francis VJA. Urgency incontinence in the female. Am $\mathcal{J}$ Obstet Gynecol 1966;94:604-8.

3 Turner-Warwick R, Brown ADS. Urodynamic evaluation of urinary incontinence in the female and its treatment. In: Turner-Warwick R, Whiteside CG, eds. Urologic clinics of North America: symposium on clinical urodynamics. Vol 6. Philadelphia: W B Saunders Co, 1979;213.

4 Frewen WK. An objective assessment of the unstable bladder of psychosomatic origin. $\mathrm{Br} \mathcal{F}$ Urol 1978;50:246-9.

5 Spielberger CD, Gorsuch RL, Lushene RE. State trait anxiety inventory. Tallahassee, Florida: State University of Florida, 1970.

6 Snaith RP, Ahmed SN, Mehta S, Hamilton M. Assessment of the severity of primary depressive illness (Wakefield self assessment depression inventory). Psychol Med 1971;1:143-9.

7 Crown S, Crisp AH. Manual of the Crown-Crisp experiential index. London: Hodder and Stoughton, 1979.

8 Crisp A, Sutherst J. Psychological factors in women with urinary incontinence. Proceedings of the International Continence Society and Urodynamic Society 1983;1:174-6.

9 Rees DLP, Farhoumand N. Psychiatric aspects of recurrent cystitis in women. Br 7 Urol 1977;49:651-8.

10 Stone CB, Judd GE. Psychogenic aspects of urinary incontinence in women. Clin Obstet Gynaecol 1978;21:807-15.

11 Freeman RM, McPherson FM, Baxby K. Psychological features of women with idiopathic detrusor instability. Urol Int 1985;40:257-9.

12 Menninger KA. Some observations on the psychological factors in urination and genitourinary afflictions. Psychoanal Rev 1941;28:117-29.

13 Pengelly AW, Booth CM. A prospective trial of bladder training as treatment for detrusor instability. Brf Urol 1980;52:463-6.

14 Truax CB, Wargo DG, Frank JD et al. Therapist empathy, genuineness and warmth and patient therapeutic outcome. Fourmal of Consulting Psychology 1966;30:395-401.

15 McDonnell RJA. Feasibility study of costing the treatment of women with micturition disorders. University of York, 1982. (MSc Dissertation.)

(Accepted 8 December 1986) 